\title{
EAD NO TOCANTINS: O EGRESSO COMO AGENTE DE TRANSFORMAÇÃO SOCIAL
}

\author{
Elizabeth Maria Lopes Toledo/Fundação Universidade do Tocantins \\ Holda Coutinho Barbosa/Fundação Universidade do Tocantins \\ Maria Fátima Viana Brasileiro/Fundação Universidade do Tocantins
}

\begin{abstract}
RESUMO: O presente texto tem como tema central a apresentação dos resultados de uma pesquisa com os egressos do curso Normal Superior Telepresencial, modalidade de ensino a distância, como agentes de transformação social. O objeto de estudo foi a primeira turma de egressos do curso Normal Superior Telepresencial, no estado do Tocantins. O instrumento utilizado foi uma entrevista aplicada pelos acadêmicos dos cursos de Pedagogia e Serviço Social. Procurou-se dissertar sobre os espaços de atuação, desafios e conquistas do profissional como um todo após a conclusão do curso e sobre os impactos sociais ocorridos no profissional e na comunidade da qual ele faz parte. Como resultado desse estudo, constatamos que o Curso Normal Superior Telepresencial - CNST representou um marco na história educacional, social e cultural do estado do Tocantins, sendo um “divisor de águas” na vida desses egressos e consequentemente na vida das pessoas dos municípios onde eles residem, possibilitando mudanças benéficas na vida pessoal e profissional dessas pessoas, bem como a oportunidade de exercerem a cidadania de forma consciente, em busca de uma sociedade mais justa, mais humana e igualitária.
\end{abstract}

PALAVRAS-CHAVE: Curso de Pedagogia. Educação a distância. Egressos. Impactos sociais.

\begin{abstract}
This study has as its main aim to discuss the results of a survey carried out with graduates who major in Education, in a distance learning course which offers video classes, as agents for social changes. The participants were the first class to graduate in this course, in the state of Tocantins. They were interviewed by other university students majoring in Pedagogy and Social Service. We seek to write about the professional field, the challenges and the achievements of these professionals as a whole after their graduation, and the social impacts these professionals have faced within the community to which they belong. As a result of this study we found out that the CNST represented a milestone in the educational, social and cultural history of the Tocantins state, working as a watershed in the life of the participants and, consequently, in the life of people who live in the cities where they live, allowing beneficial changes in the personal and professional lives of these people, as well as the opportunity to exercise full citizenship, in the search for a more fair, human and equal society.
\end{abstract}

KEYWORDS: Pedagogy course. Distance learning. Graduates. Social impacts.

\section{INTRODUÇÃO}

A Educação a Distância, na atualidade, consagra uma nova alternativa de ampliação do 
ensino superior. A Lei de Diretrizes e Bases da Educação Nacional, Lei n. 9.394/96, em seu artigo 87, parágrafo 4, estabeleceu que, ao final da década de 1990, somente seriam admitidos professores na Educação Básica habilitados em nível superior ou aperfeiçoados por formação em serviço. Por força dessa determinação legal, surgiram em todas as regiões do Brasil programas de formação docente a distância, particularmente aqueles destinados a formar os professores que já atuavam nos anos iniciais do ensino fundamental, bem como para outros interessados.

A formação em nível superior desses professores é, sem dúvida, um desafio para o país. Se, por um lado, essa é a formação almejada pelo movimento dos educadores, por outro, há discordâncias a respeito das normatizações e das ações que foram encaminhadas para oferecê-la, principalmente no que se refere à modalidade a distância.

A distância não é mais a falta física, ela é um estado de espírito e está em cada um de nós, nos nossos sentimentos e não quão perto ou longe o outro esteja de nós. Em EaD, não há distância entre o professor e o aluno se ela for tratada de forma a não comprometer a interação entre eles. A Educação a Distância poderá ser considerada como uma educação que pode promover a aproximação.

As diferenças conceituais sobre a EaD se devem mais à evolução natural ocorrida nos sistemas de Educação a Distância ao longo do tempo do que propriamente a eventuais divergências a respeito do conceito básico. Os conceitos atrelam-se, pois, aos processos evolutivos da EaD; assim sendo, há autores que focalizam a questão da distância física entre professor e aluno, outros focalizam os recursos tecnológicos empregados, ou mesmo a forma como tais recursos são usados para favorecer a comunicação de forma unilateral ou bilateral.

Com a modalidade a distância, é importante ter uma preocupação permanente no sentido de primar pela qualidade dos cursos oferecidos para que isso não venha a ser outro fator que possa comprometer a formação de professores para a educação básica.

No ano de 2001, o estado do Tocantins iniciou a educação superior na modalidade a distância, denominada, nessa época, “ensino telepresencial”, com três cursos, dentre eles, o de Pedagogia. Uma das finalidades foi atender à demanda de formar professores para atuar na educação básica, pois essa era uma das grandes carências do estado.

Em 2009, foi desenvolvida uma pesquisa por um grupo de professores da Unitins com o objetivo de investigar e diagnosticar as possíveis mudanças ocorridas no contexto socioeconômico em diferentes regiões do Estado do Tocantins, a partir da conclusão do curso Normal Superior na modalidade EaD. A pesquisa visou a subsidiar as contribuições dos egressos do curso Normal Superior Telepresencial para o desenvolvimento não apenas educacional, mas também em outros âmbitos sociais em que eles estão inseridos, bem como fornecer dados objetivos para as ações da Unitins no âmbito da educação superior.

\section{EDUCAÇÃO A DISTÂNCIA NO ESTADO DO TOCANTINS: RUPTURA DE BARREIRAS}

O mais novo estado brasileiro, criado pela Emenda Constitucional no seu art. 13 das Disposições Constitucionais Transitórias, a partir da divisão do então estado de Goiás, em 05/10/1988, teve suas políticas públicas voltadas para ações de expansão do acesso à educação por 
meio da implantação de vários projetos e programas, dentre eles, a educação superior a distância.

Sintonizados com as mudanças sociais e legais ${ }^{i}$, e buscando coerência aos paradigmas emergentes no campo da gestão da educação, deu-se início em 2001 a oferta do Curso Normal Superior $^{\text {ii }}$ na Modalidade Telepresencial - CNST - aprovado como curso experimental pelo Conselho Estadual de Educação, com o objetivo de formar professores para os anos iniciais do Ensino Fundamental, tendo em vista as demandas da sociedade regional, no quadro contemporâneo de confluência com os dispositivos tecnológicos e comunicacionais da chamada sociedade da informação.

O Curso Normal Superior Telepresencial (CNST) da Unitins teve duração de três (03) anos divididos em seis (06) semestres, sendo suas aulas transmitidas, ao vivo, para as três (03) turmas com teleaulas diárias através de antena e sinal exclusivo. Ele contava com suporte técnicoacadêmico toll free (0800), com malotes via correio e o serviço de tutoria permanente.

A autorização para implantação e funcionamento do CNST ocorreu em 28 de setembro de 2000, Parecer $n^{\circ}$ 153/2000, Processo $n^{0}$ 2000/2700/004128 do Conselho Estadual de Educação/Secretaria do Estado da Educação e Cultura do Tocantins. E esse foi apenas o primeiro passo para o posterior credenciamento da Unitins, pelo MEC, para a oferta de Educação a Distância.

Em 2003, ano de conclusão da primeira turma do CNST - autorização para início do Curso de Pedagogia - eram diretamente atendidos 90 municípios do Estado e mais de sete mil (7.000) alunos concluíram o Curso Normal Superior nas turmas oferecidas nos três turnos.

Esse projeto foi desenvolvido totalmente a distância, não previa atividades semipresenciais como sugere, por exemplo, Landim (1997). O autor afirmar que a EaD pressupõe a combinação de tecnologias novas e tradicionais para propiciar o estudo em grupos ou individualmente nos diversos ambientes (como os locais de trabalho ou residências), por meio de tutoria e orientação a distância, com algumas atividades presenciais, tais como reuniões de grupo de estudo para tirar dúvidas e também para avaliação.

No caso específico da Unitins, os alunos se reuniam nas telessalas com o objetivo único de assistir às teleaulas e realizar as avaliações. A alternativa dos cursistas constituírem grupos de estudo ou outras atividades coletivas ficava a cargo dos próprios alunos.

Na educação, o diálogo implica o reconhecimento do outro, com seus valores, com sua história, como ser igual. Ele é princípio da alteridade, o que não significa a concordância cega, mas também a não arrogância, postulado daqueles que não esperam ou não permitem que o outro dê os seus próprios passos. Educadores e educandos são sujeitos históricos capazes de dialogar e construir juntos uma sociedade melhor.

Se esta é a realidade e a necessidade no ensino presencial, muito mais o é no ensino a distância, quando a mediação ocorre por meio de diferentes canais comunicativos e a autonomia do aluno é imperativa para a elaboração de conhecimentos válidos para a atuação consciente no âmbito educacional, profissional e social.

O curso de Pedagogia na modalidade telepresencial foi um grande atrativo para boa parte da população tocantinense; para muitos, foi a primeira chance de ingresso na educação superior. Por se tratar de uma modalidade a distância com as aulas transmitidas ao vivo pela TV, despertou além do interesse de qualificação profissional, a curiosidade pelo novo - o mito que a TV alimenta -, além do ceticismo por parte de muitos quanto à qualidade do curso oferecido e a dúvida sobre a validade dele. 


\section{CNST: O EGRESSO COMO AGENTE DE TRANSFORMAÇÃO SOCIAL}

O público alvo, objeto dessa pesquisa, foi constituído pelos profissionais que cursaram a primeira turma do CNST da Unitins no período de 2001 a 2003. O perfil dos acadêmicos levantado pela universidade, na ocasião da matrícula, mostrou que ao ingressarem na universidade alguns já eram professores da educação básica e não tinham habilitação, e outros atuavam como profissionais em vários segmentos da sociedade. Nossa curiosidade foi saber como esses profissionais (egressos) continuaram sua vida profissional após a conclusão do curso; que mudanças o curso provocou em suas vidas do ponto vista profissional, social e pessoal. Aí está a razão de nossa pesquisa.

O curso de Pedagogia, desde sua origem em 1939, vem passando por transformações que objetivam conceituar a identidade do profissional pedagogo. No entanto, sempre teve definido como seu objeto de estudo e finalidade precípua os processos educativos em escolas e outros ambientes, sobremaneira a educação de crianças nos anos iniciais de escolarização, além da gestão educacional (BRITO, 2009).

Atualmente, o debate em torno da identidade do profissional pedagogo é ainda maior, uma vez que a demanda educacional da sociedade moderna é mais intensa e exige uma educação formal de grande qualidade, mas também competências que ultrapassem os limites da sala de aula e possam abranger a formação do indivíduo trabalhando o educacional, o social e o cultural.

A prática pedagógica está ligada ao processo social; portanto, é um fenômeno constante de modificações. A pedagogia investiga os fatores reais e concretos que ocorrem para a formação humana, no seu desenvolvimento histórico, para daí extrair objetivos sociopolíticos e formas de intervenção organizativa e metodológica em torno dos processos que correspondem à ação educativa (LIBÂNEO, 2008).

Segundo o mesmo autor, o campo de atuação do profissional formado em Pedagogia é tão vasto quanto são as práticas educativas na sociedade. Em todo lugar em que houver uma prática educativa com caráter de intencionalidade, há aí uma Pedagogia. Ao realizar essa pesquisa, foi muito gratificante perceber que não só aqueles que já eram professores, como também os outros profissionais egressos que atuavam em áreas diversas, estavam preocupados com a prática social dos conhecimentos adquiridos e construídos no sentido de contribuir para melhorar seu contexto.

Além de ampliar o campo de atuação do profissional na educação, o Curso Normal Superior Telepresencial proporcionou ao egresso a conquista da construção de sua identidade profissional, em virtude do seu trabalho, de seus saberes acumulados e postos em prática, o que conferiu a ele um novo significado, uma nova representação na sociedade.

Nesse sentido, Pimenta (2002, p. 77) afirma que:

Uma identidade profissional se constrói, pois, com base na significação social da profissão, na revisão constante dos significados sociais da profissão, na revisão das tradições, mas também na reafirmação de práticas consagradas culturalmente que permanecem significativas [...]. Constrói-se, também, no significado que cada professor, enquanto ator e autor, conferem à atividade docente em seu cotidiano, com base em seus valores, em seu modo de situar-se no mundo, e sua história de vida, em suas representações, em seus saberes, no sentido que tem em sua vida o 'ser professor'.

Nesse contexto, o trabalho do pedagogo vai sofrendo modificações e sua profissão torna-se estratégica, pois um leque de atuação vai se abrindo. Torna-se necessário que o pedagogo 
adquira um perfil com saberes que o auxiliem no seu fazer pedagógico. Esses saberes darão sustentação ao seu trabalho e à sua própria identidade, que se configura de acordo com seu desempenho pedagógico. Nessa perspectiva, a construção desse perfil caracteriza-se como um processo dinâmico, mas ao mesmo tempo complexo. Essa complexidade se estrutura por referenciar o aspecto profissional e o pessoal por meio da interação com as situações da profissão e também por compreender o pedagogo como sujeito do conhecimento, capaz de construir saberes e desenvolver habilidades profissionais que permitem a construção de sua própria identidade, além de reconhecer-se como profissional apto a atuar em espaços formais e não formais.

\section{METODOLOGIA DA PESQUISA}

O universo da pesquisa foi constituído por 28 municípios, correspondendo a 20\% dos 139 municípios do estado do Tocantins. Foram aplicados mil quinhentos e noventa e um (1.591) questionários, respondidos por egressos do CNST, residentes nesses municípios. Os instrumentos foram aplicados por acadêmicos que, na época da realização da pesquisa, estavam matriculados nos cursos de Pedagogia e Serviço Social, e que se dispuseram a localizar os ex-alunos e aplicar o questionário.

A abordagem metodológica, adotada na presente pesquisa, foi predominantemente qualitativa, pois os objetos de pesquisa nas ciências humanas, conforme Laville e Dionne (1999, p. 32), "são dotados de liberdade e consciência, pois, a realidade dos fatos humanos é delas amplamente tributária, e raramente se pode determiná-la, em toda sua complexidade, sem considerar os múltiplos elementos que a compõem”.

Por isso, para desvelar os impactos do CNST, torna-se indispensável uma reflexão sobre o perfil dos egressos e os impactos sociais após a conclusão do referido curso. A reflexão qualitativa, neste sentido, não se ocupou somente dos fenômenos em si, mas das estruturas internas da consciência pelas quais os fenômenos são compreendidos, constituindo as significações da realidade em sua complexidade, na medida em que esta é carregada de valores sociais, políticos, econômicos, culturais, jurídicos, dentre outros.

Sobre a abordagem qualitativa, convém ressaltar que, como destaca Chizzotti (2006), vários teóricos resumiram as transformações e progressos no século $\mathrm{XX}$, dentre eles, Denzin e Lincoln (2006). Entretanto, não existe uma metodologia predominante, definida como qualitativa, ou seja, coexiste "uma gama de questões teórico-metodológicas abertas pelos pesquisadores qualitativos” (2006, p. 56). Portanto, a presente pesquisa conjugou diferentes métodos e técnicas para atingir os objetivos estabelecidos.

Destaca-se, ainda, que o desenvolvimento do estudo qualitativo supõe um corte temporal e espacial do fenômeno, feito pelos pesquisadores. Esse corte permitiu definir o campo e a dimensão em que ocorreu a coleta de dados, ou seja, o universo investigado e as técnicas para análise e descrição dos dados coletados. 


\section{MATERIAL E MÉTODOS}

Para a realização dessa investigação, foram definidos os procedimentos da presente pesquisa qualitativa tendo como parâmetros os seguintes itens:

1. Revisão de literatura - a respeito da área de estudo, educação a distância, tecnologias de informação e comunicação, capitalismo, trabalho e educação, com teóricos das áreas como Gadotti (1995), Saviani (1991, 2002), Kenski (2003, 2005), Castels (1999) e Litwin (2001). A pesquisa foi definida como histórico-comparativa do contexto socioeconômico em diferentes regiões do Estado do Tocantins, com uma amostra de $50 \%$ dos alunos que concluíram o curso Normal Superior na modalidade EaD nos anos 2003 e 2004.

2. Levantamento na Secretaria Acadêmica da Unitins - informando as telessalas onde foi ofertado o CNST em 2003 e 2004. Para efeito dessa pesquisa, foi utilizada uma amostragem de $20 \%$ dos municípios.

3. Seleção dos municípios envolvidos na pesquisa - levando em consideração a localização por regiões geográficas, tendo como referencia $20 \%$ dos 139 municípios existentes, o número de telessalas com as respectivas quantidades de egressos.

4. Aplicação de questionário contendo dezoito (18) questões, sendo quatro (04) discursivas e 14 objetivas. As questões podem ser categorizadas em: Perfil dos egressos, Situação do Trabalho e Situação Social (após o curso).

Foram aplicados um mil quinhentos e noventa e um (1.591) questionários respondidos por egressos residentes nos municípios de: Alvorada, Ananás, Araguaçu, Araguacema, Araguaina, Araguatins, Barrolândia, Bernardo Sayão, Colmeia, Conceição do Tocantins, Dianopólis, Gurupi, Guaraí, Miracema, Monte do Carmo, Natividade, Novo Acordo, Palmas, Palmeiropolis, Paraíso, Paranã, Pedro Afonso, Ponte Alta do Tocantins, Porto Nacional, Praia Norte, Presidente Kenndy, Rio Sono, Taguatinga, Tocantinópolis e Xambioá.

Os dados colhidos a partir da tabulação desses questionários permitiram uma análise quantitativa, como também qualitativa, por meio da análise temática de conteúdos, que, segundo Laville e Dionne (1999, p. 214), "consiste em desmontar a estrutura e os elementos desse conteúdo para esclarecer suas diferentes características e extrair sua significação".

5. Análise temática dos conteúdos. Depois da coleta dos dados, foi feito um estudo minucioso do conteúdo, das palavras e frases que os compõem, visando procurar-lhes o sentido, captar-lhes as intenções, comparar, avaliar, descartar o acessório, reconhecer o essencial e selecioná-lo em torno das ideias principais.

Uma das primeiras tarefas das pesquisadoras foi efetuar um recorte dos conteúdos em elementos. Esses elementos constituíram as unidades de análise. Certamente, nem todas as palavras ou unidades de análise, definidas a priori, foram aproveitadas ou tiveram interesse para a realização da análise.

O objetivo foi reunir os elementos repetidos nas respostas dos egressos em função de sua significação, ensejando que "esses elementos sejam portadores de sentido em relação ao material analisado e às intenções da pesquisa" (LAVILLE; DIONNE, 1999, p. 217). Cada uma dessas unidades, que na prática representa fragmentos do conteúdo maior, deve ter sentido completo em si. É como se cada trecho do texto em análise trouxesse em si mesmo uma parte do significado completo do texto. No momento do recorte desses elementos, os pesquisadores precisaram se deter 
em palavras-chave que traduziram as ideias ou o sentido ligado, direta ou indiretamente, ao objeto da investigação, sem perder de vista os objetivos da pesquisa, nesse recorte intencional.

\section{RESULTADOS E DISCUSSÃO}

A análise e interpretação dos dados nesta pesquisa deram-se a partir dos resultados alcançados mediante a tabulação das questões objetivas e transcrição das questões discursivas, com apanhado de seu conteúdo e categorização descrita no item material e métodos. Os resultados apresentados se deram em torno da atuação profissional dos egressos após a conclusão do curso e os impactos sociais causados nos municípios.

\subsection{Atuação dos egressos: após o Curso Normal Superior Telepresencial - CNST}

\subsubsection{Atuação no magistério}

Ao analisar sobre a atuação posterior a conclusão do curso, observou-se que dos egressos que participaram da pesquisa, 644 dos continuaram a atuar na função docente correspondendo um percentual de 59\%; enquanto 196, equivalente a $18 \%$, enfatizou que o curso contribuiu para o desempenho de outra área/função. 164 egressos, 15\%, continuaram em outras funções pedagógicas e, desses, 44 , apenas $4 \%$, deles permaneceram atuando em funções gerenciais. Já outros 44 egressos (4\%), que não atuavam no magistério, permaneceram fora dele por questões diversas, conforme o Gráfico 1 a seguir:

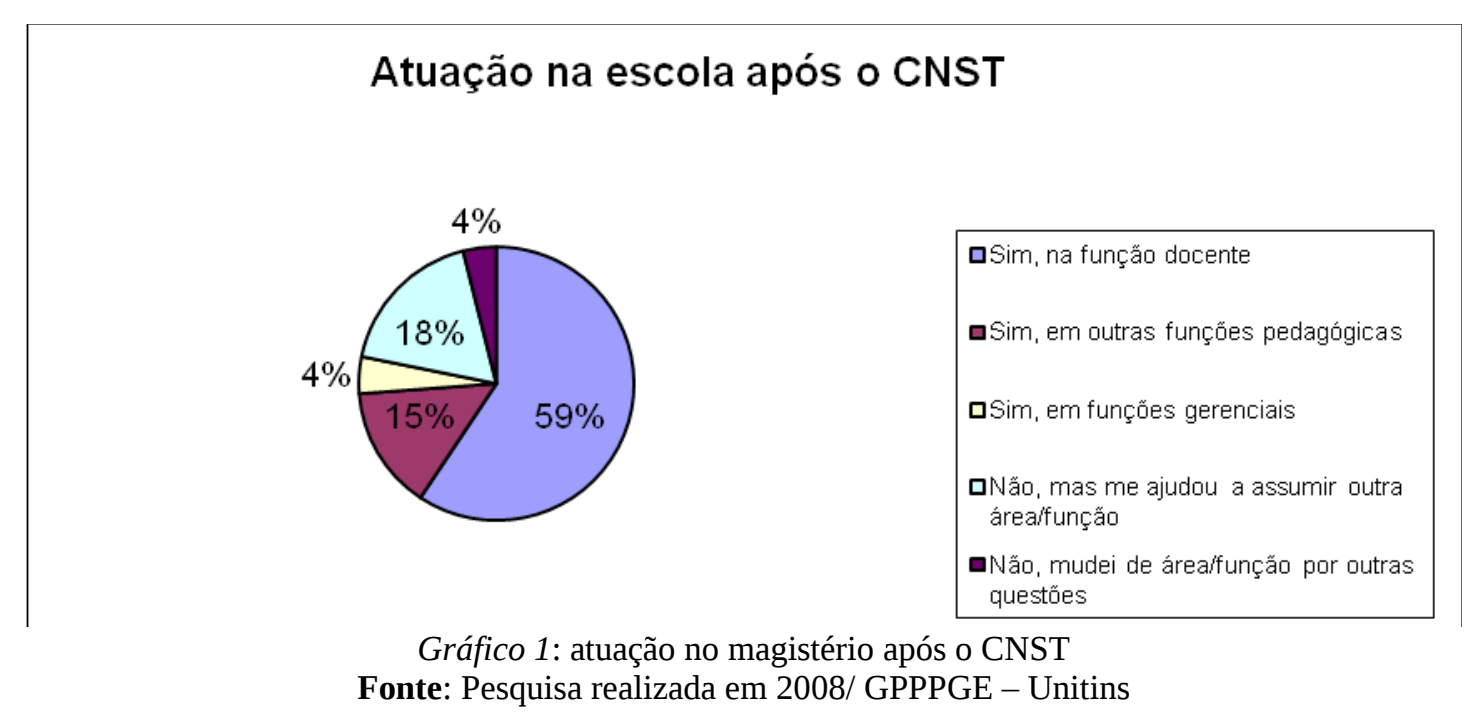

\subsubsection{Impactos sociais: $\mathrm{o}$ antes e o depois do CNST}

Ao analisar os impactos sociais do Curso Normal Superior Telepresencial, recorreu-se à análise comparativa no índice salarial antes e após o curso, conforme os Gráficos 2 e 3. 


\section{Salário mensal no magistério antes do CNST}
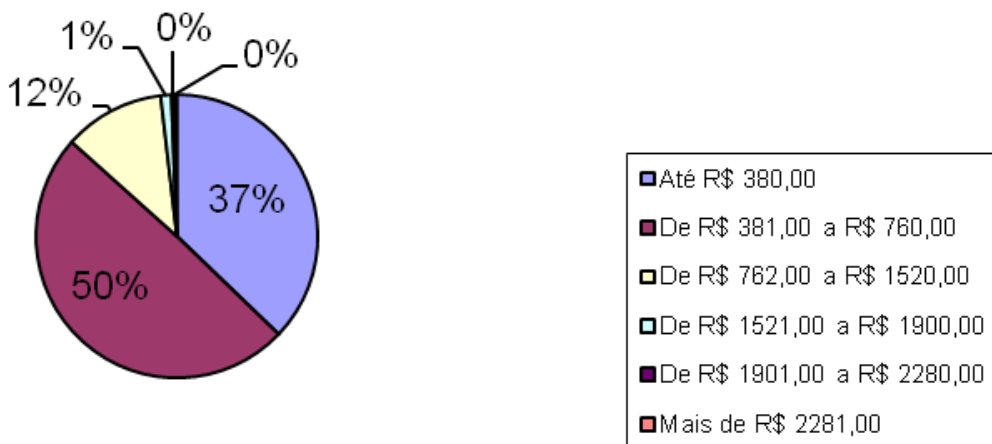

Gráfico 2: salário mensal docente antes do CNST

Fonte: Pesquisa realizada em 2008/ GPPPGE - Unitins

A análise nessa questão foi estabelecida por faixas salariais. Assim, constatou-se que $37 \%$ dos egressos continuavam recebendo um salário mínimo mesmo tendo concluído o curso superior. Entretanto, depois da conclusão do CNST, a situação modificou-se significativamente em relação ao menor teto salarial, ou seja, dos $37 \%$, apenas $5 \%$ permaneceram ganhando o salário mínimo (R\$ 380,00), como demonstra o Gráfico 3.

\subsubsection{Salário mensal}

O salário mensal dos egressos do CNST, conforme o Gráfico 3 a seguir mostrou que, antes do ingresso no curso, 37\%, isto é, 404 egressos recebiam até um salário mínimo, evidenciando que, sem uma formação superior, o docente não era valorizado profissionalmente e nem em termos salariais. 546 egressos, equivalendo a um percentual de 50\%, recebiam até dois salários, mostrando assim que metade dos entrevistados, mesmo com um nível de magistério médio, já recebia mais de um salário. Nas demais faixas salariais - a partir de dois salários -, o percentual diminui, ou seja, apenas $12 \%$ dos egressos recebiam esse valor. Acima de cinco salários, conforme os resultados, a faixa salarial é inferior a 1\%, correspondendo a 11 ex-alunos do curso.

\section{Salário mensal no magistério, depois de realizar o CNST}

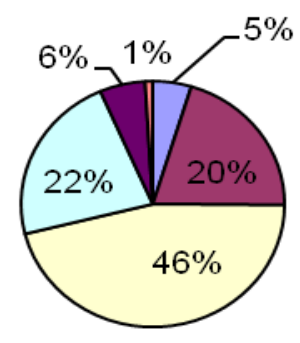

$$
\begin{aligned}
& \text { 口Até } \mathrm{R} \$ 380,00 \\
& \text { a } \mathrm{De} R \$ 381,00 \text { a } \mathrm{R} \$ \\
& 760,00 \\
& \text { 口De R \$ 762,00 a R\$ } \\
& 1520,00 \\
& \text { 口De R \$ 1521,00 a R \$ } \\
& 1900,00 \\
& \text { - De R\$ 1901,00 a R \$ } \\
& \text { 2280,00 }
\end{aligned}
$$

Gráfico 3: salário mensal docente depois do CNST

Fonte: Pesquisa realizada em 2008/ GPPPGE - Unitins 
Na segunda faixa salarial - até dois salários -, o percentual era também considerável, ou seja, 218 ex-alunos (20\%) recebiam esse valor, conforme justificativa anterior. Na terceira faixa foi constatado que, ao fazer o CNST, o salário mensal do magistério melhorou consideravelmente, conforme atestaram os resultados. De 1.092 egressos entrevistados, 502 afirmaram que, após o curso, seus salários ultrapassaram três salários mínimos, correspondendo a 46\% desses egressos, o que confirma a importância da realização do curso superior em suas vidas.

$\mathrm{Na}$ quarta faixa, acima de quatro salários mínimos, equivalente a 22\%, ou seja, 240 egressos recebiam nessa faixa salarial, o que confirmou a valorização do curso superior na vida pessoal de cada ex-aluno. Nas demais faixas salariais (6\%, 5\% e 1\%), embora com percentual reduzido, constatou-se que a melhoria salarial foi determinante para os egressos com formação superior.

\subsubsection{Percepção dos egressos sobre os impactos sociais do CNST}

Os egressos foram investigados sobre a existência de relação entre a realização do CNST e a posição profissional e social deles a partir dessa conquista acadêmica.

Ao fazer o recorte dos conteúdos das respostas às questões que buscaram captar a percepção dos entrevistados sobre as repercussões do CNST, obteve-se as categorias de análise apresentadas no Quadro 1 a seguir:

\begin{tabular}{|c|c|}
\hline \multicolumn{2}{|c|}{ Categorias emergentes na análise de conteúdo } \\
\hline \multirow{4}{*}{$\begin{array}{l}\text { 1. Realização do Curso Normal Superior Telepresencial } \\
\text { e atuação profissional. }\end{array}$} & a. Ampliação de conhecimento \\
\hline & b. Aprovação em concurso público \\
\hline & c. Aumento salarial \\
\hline & d. Inovação/segurança no exercício profissional \\
\hline \multirow{3}{*}{$\begin{array}{l}\text { 2. Repercussão do Curso Normal Superior } \\
\text { Telepresencial na ocupação atual. }\end{array}$} & a. Empregabilidade \\
\hline & b. Valorização pessoal e profissional \\
\hline & c. Exercício da cidadania \\
\hline \multirow{3}{*}{$\begin{array}{l}\text { 3. Curso Normal Superior Telepresencial e exemplos de } \\
\text { exercício da cidadania. }\end{array}$} & $\begin{array}{l}\text { a. Elaboração e desenvolvimento de projetos } \\
\text { sociais. }\end{array}$ \\
\hline & $\begin{array}{l}\text { b. Visão mais consciente da escola, da sociedade e } \\
\text { do papel do professor. }\end{array}$ \\
\hline & $\begin{array}{l}\text { c. Ajuda aos filhos e demais familiares. } \\
\begin{array}{l}\text { d. Abertura de novos horizontes profissionais e } \\
\text { sociais. }\end{array}\end{array}$ \\
\hline \multirow{4}{*}{$\begin{array}{l}\text { 4. Comentários, críticas ou sugestões para melhoria dos } \\
\text { cursos a distância da Unitins. }\end{array}$} & a. Críticas \\
\hline & b. Elogios \\
\hline & c. Sugestões \\
\hline & d. Omissões \\
\hline
\end{tabular}

Quadro 1: Análise e interpretação dos dados/questionário

Fonte: GPPPGE / Unitins

As respostas abertas, cujo conteúdo foi analisado de acordo com as temáticas definidas nas categorias supracitadas, mostraram que os egressos perceberam de forma muito clara que o curso representou um marco muito importante na ascensão profissional.

De acordo com Frigotto (2002), a relação entre trabalho e educação pode ser 
considerada arcaica por muitos pesquisadores da área; entretanto, em algumas situações é relevante usar essa abordagem, uma vez que permite posicionar e abrir caminhos para novos debates como, por exemplo, com a teoria de Habermas, para quem a centralidade do trabalho está no "campo da comunicação e da linguagem na produção social da existência humana” (FRIGOTTO, 2002, p. 186).

Isso corrobora a concepção de que se a educação não pode ser considerada redentora da sociedade, tampouco a transformação dessa sociedade poderá ocorrer sem o desenvolvimento educacional. Nesse sentido, ao buscar compreender os impactos sociais do CNST, observou-se que, em relação à atuação profissional, os entrevistados afirmaram que o curso ajudou-os a ampliar os conhecimentos, e ainda, que os ajudou a obter aprovação em concurso público estadual ou municipal; portanto, causou interferência direta no aumento salarial.

Em “A cidadania negada”, Frigotto e demais autores, como Garcia Canclini, abordam o paradoxo entre educação e democracia social, pois

A hegemonia está enraizada nesta hegemonia enraizado: a mudança da forma de internalização da desigualdade social e das disposições inconscientes no corpo, na consciência de que é possível e que o inatingível (García Canclini 1984 apud BIRGIN, 2002, p. 231 $\left.1^{\mathrm{iii}}\right)$.

A cidadania, nesse caso, tanto pode ser ampliada pelo acesso à educação, como pode ser negada a tantos que a ela não têm acesso e condição de permanência com sucesso.

A educação, para ser promotora de cidadania, precisa, também, ajudar o sujeito a aperfeiçoar sua prática profissional, como confirmou outro grupo de egressos ao afirmar que o curso ajudou-os a implementar inovações na sua atuação docente, o que, em alguns casos, significou a promoção para cargos/funções de coordenação pedagógica, gestão escolar ou educacional.

Indagados, ainda, sobre a percepção a respeito das relações entre o CNST e a mudança social ocorrida, 91\% dos entrevistados afirmou que tais mudanças se deveram à conclusão do curso e à utilização dos conhecimentos advindos dele.

Essa é uma visão que poderia ser considerada excessivamente otimista sobre os impactos sociais da educação; entretanto, considerando o contexto social do Estado do Tocantins e o quanto os egressos expressaram de forma espontânea sua satisfação, cabe destacar que o curso realmente ajudou o desenvolvimento pessoal e profissional de seus egressos, bem como de suas comunidades.

Ainda, sobre os impactos do CNST na atuação profissional, buscou-se compreender, independentemente de haver ou não relação, se os egressos percebiam influência do CNST na sua atual ocupação. Os temas recorrentes nas respostas dos entrevistados culminaram nas seguintes categorias: empregabilidade, valorização pessoal e profissional e exercício da cidadania.

Embora esses sejam conceitos muito amplos e passíveis de enfoques diferenciados conforme os diversos autores, nessa pesquisa foram adotadas as seguintes concepções e relações: cidadania é compreendida conforme definição de Saviani (2002), para quem a mudança trazida pela globalização tem criado um novo cidadão que não é só nacional, mas também global, e que a mídia é uma instituição importante para desafiar poderes dominantes, como as corporações. O autor assinala, ainda, que o neoliberalismo não tem o completo controle dessa nova situação e que o emergente "cidadão global” tem o potencial de reformar a sociedade. 
Os egressos destacaram temas importantes como exemplos de exercício de cidadania: elaboração e desenvolvimento de projetos sociais, visão mais consciente da função social da escola, da sociedade e do papel do professor, auxílio e incentivo aos filhos e demais familiares e abertura de novos horizontes profissionais e sociais, ou seja, do exercício consciente de cidadania.

Os entrevistados escolheram, dentre as alternativas apresentadas, 12 situações em que 0 CNST significou ganhos profissionais e pessoais, conforme o Gráfico 4 a seguir.

\section{Ganhos conquistados como CNST além da melhoria na atuação na vida profissional}

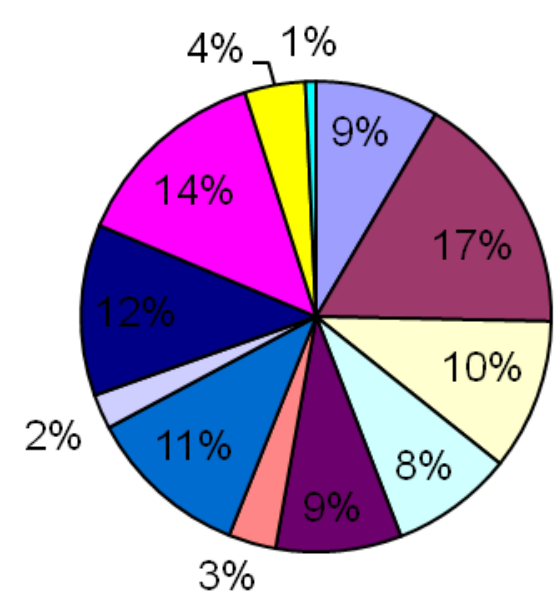

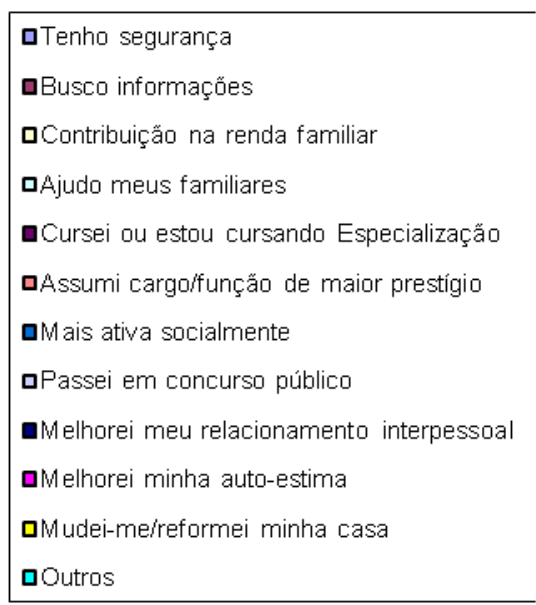

Gráfico 4: Ganhos advindos do CNST

Fonte: Pesquisa realizada em 2008/ GPPPGE - Unitins

Observou-se que, embora os egressos do CNST tivessem demonstrado satisfação com os benefícios advindos do curso concluído, apenas 8\% deles afirmaram ter passado em concurso público e somente 3\% alegaram ter galgado cargos de maior prestígio. Enquanto 17\% destacaram o fato de ter aprendido a buscar novas informações, $12 \%$ afirmaram ter melhorado sua autoestima e apenas $11 \%$ asseguraram que, com o curso concluído, tornou-se socialmente mais ativo, significando que os bens culturais prevaleceram sobre os bens materiais.

Saviani (2002) analisa situações semelhantes à encontrada na presente pesquisa a partir das concepções de disparidades econômicas e exclusão difundida, criadas pela forma atual do capitalismo global e representadas por conceitos como a "qualidade total". O autor ainda afirma que esse estado é evidente no "consumo destrutivo e supérfluo" (SAVIANI, 2002, p. 134) das classes ricas, as quais têm conduzido às lutas retomadas pelos trabalhadores e grupos marginalizados por esse sistema, num esforço de demonstrar a desigualdade e a injustiça da sociedade contemporânea. Assim, as classes trabalhadoras somente podem contar com uma melhoria de vida, mediante seu esforço pessoal de crescimento, geralmente via formação acadêmica.

Parafraseando Saviani (2002, p. 136), as pessoas das regiões latino-americanas têm se tornado “mais pobres e mais educadas”. Ao fazer essa afirmação, o autor discute que a educação, no sistema econômico atual, é concebida como uma escolha individual em vez de um direito, e que a promessa de muitos empregos tem sido substituída por uma escolha própria e a promessa de 
“empregabilidade”. Parece ser esse o caso dos egressos do CNST.

A pesquisa revelou, também, a percepção dos familiares e amigos em relação ao desenvolvimento pessoal e relacionamento interpessoal dos egressos em relação a outras pessoas e a grupos de pessoas. Foi apontada, ainda, melhoria na comunicação oral e escrita, elevação da autoestima, mais iniciativa e maior confiança no que faz e segurança no que diz, maior poder de argumentação nas discussões, maior participação na vida familiar e mais solidariedade com amigos e vizinhos.

Sobre a relação da teoria aprendida e as experiências e conhecimentos adquiridos durante o curso e a aplicação na prática desses em sua vida profissional, a maioria dos egressos, $61 \%$ (670 ex-alunos), afirmaram que utilizam muito no seu cotidiano profissional. Ao passo que 37\%, (406) dos egressos, professores, enfatizaram que aproveitam esses aspectos em sua prática pedagógica, nas situações de interação professor-aluno e aluno-aluno, independente do tema que está sendo desenvolvido. Apenas $2 \%$ não conseguiam utilizar os conhecimentos adquiridos no curso.

\section{Prática em relação aos conhecimentos e experiências adquiridas durante o curso}

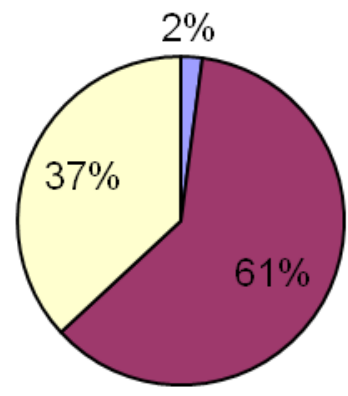

口Nẫo tenho conseguido aproveitar

esses conhecimentos.

口Aproveito-os, sempre que percebo que eles têm alguma relaçẫo com

a atividade profissional que exerço atualmente.

口Aproveito-os com meus alunos em qualquer situaçẫo de interação, professor-aluno, aluno-aluno. independente do tema tratado.

Gráfico 5: a prática dos conhecimentos e experiências adquiridos durante o CNST Fonte: Pesquisa realizada em 2008/ GPPPGE - Unitins

\subsubsection{Comentários: elogios, críticas e sugestões dos egressos}

Os egressos investigados teceram elogios, críticas e emitiram sugestões sobre o CNST. Um índice de $31 \%$ desses entrevistados se abstiveram de enunciar qualquer parecer; entretanto, a maioria, $46 \%$, elogiou muito o curso no que se refere à relação teoria/prática para quem já é professor, mas, principalmente, no que se refere às possibilidades de novas opções no mercado de trabalho, inclusive na própria comunidade da qual fazem parte.

Como o público dessa pesquisa é constituído por adultos trabalhadores e estão em busca de novos conhecimentos que complementem suas próprias experiências, tomaram a decisão de buscar o que é importante para sua vida e seu trabalho, o que potencializa o papel ativo no seu processo de aprendizagem. Se tornaram, portanto, mais participativos e atuantes como cidadãos.

Dessa forma, é possível conceber, como Litwin (2001, p. 70-71), que: 
[...] as pessoas que aceitam fazer parte dessas propostas educativas encontram nelas uma oportunidade para participar dos sistemas simbólicos da cultura. Para adultos, cujo acesso ao conhecimento sistematizado está limitado por diferentes fatores, tal possibilidade constitui a pedra fundamental de novos projetos pessoais e sociais.

Esse posicionamento reforça as vantagens dos cursos na modalidade a distância, na qual alunos adultos se comprometem, pois "sentem na pele" a necessidade de aprender, tanto para melhorar sua atuação profissional quanto para sua satisfação pessoal. Responsabilidade, quesito fundamental para o sucesso profissional, apresenta-se como benefício nos cursos a distância, em que é imprescindível que os cursistas assumam a postura de "sujeitos ativos de suas próprias aprendizagens”.

Todavia, nem todos os comentários foram elogiosos. Mesmo enaltecendo o trabalho dos professores e a relevância dos conteúdos por eles ensinados, 16\% enfatizaram a necessidade de melhorar a interação entre professores, alunos e tutores, principalmente no que tange ao perfil e à capacitação dos tutores nas telessalas.

Na modalidade EaD, os alunos que se matriculam e permanecem até a fase do estágio e conclusão do curso, o fazem porque já adquiriram a consciência e a autonomia necessárias, compreendidas, de acordo com Freire (1970), como o processo de produzir e de adquirir conhecimentos, através do qual o sujeito termina também por aprender a tomar distância dos objetos, maneira contraditória de se aproximar deles. Desses estudantes, 16\%, conscientes das deficiências apresentadas pelo sistema, sugeriram melhoria para os próximos cursos como construção de bibliotecas com um acervo bibliográfico específico para cada área, de forma a proporcionar aos acadêmicos possibilidade de aprofundar seus conhecimentos por meio da pesquisa, considerando que a maioria não tem acesso à internet.

Por fim, apenas 7\% dos pesquisados fizeram algumas críticas em relação à modalidade a distância e ao curso alegando que aprenderam pouco, que faltou interatividade com os professores, além de orientações aos alunos sobre como estudar nessa modalidade.

O resultado dessa pesquisa poderá subsidiar as decisões da universidade quanto à organização dos cursos de graduação que serão posteriormente ofertados pelo sistema EaD/Unitins. As percepções, críticas e sugestões deverão constituir oportunidade de crescimento e melhoria da educação a distância como instrumento de democratização e desenvolvimento social.

\subsubsection{Formação continuada após o CNST}

Grande parte dos egressos deu continuidade aos seus estudos após a conclusão do CNST. Dos participantes da pesquisa, 56\%, ou seja, 611 deles fizeram curso de especialização lato sensu; 273 fizeram outro curso de graduação, equivalente a 25\% deles; 196 egressos, isto é, 18\% iniciaram o curso Normal Superior, mas, concluíram outros cursos, e apenas 1\%, isto é, 11 egressos fizeram cursos de especialização stricto sensu, conforme Gráfico 6 a seguir: 


\section{Cursos realizados após a conclusão do CNST}

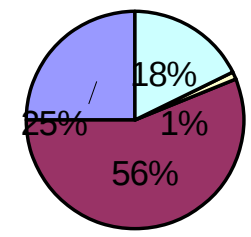

$\square$ Outro curso de graduação

$\square$ Curso de Especialização latu sensu

$\square$ Curso de especialização strictu sensu

$\square$ Outros (especificar)

Gráfico 6: Formação após o CNST

Fonte: Pesquisa realizada em 2008/ GPPPGE - Unitins

Constatou-se por meio dos números a importância que o curso Normal Superior teve na vida dos acadêmicos, pois demonstrou que aqueles que acreditaram no curso e depositaram confiança na instituição se aperfeiçoaram em sua área de atuação além de servir de alavanca para galgar outros patamares na vida pessoal e profissional.

\section{CONSIDERAÇÕES FINAIS}

O Estado do Tocantins foi agraciado por mudanças em seu contexto social e educacional com a criação do curso Normal Superior Telepresencial, na modalidade a distância. A realidade educacional no Estado antes do acesso e conclusão de um curso superior era considerada quase uma 'calamidade' em se tratando de educação nos espaços formais e não formais, bem como em termos sociais, uma vez que grande parte da população vivia de forma quase desconectada do mundo, ou seja, tinha uma visão muito restrita de coisas, espaços e pessoas. Essa realidade era peculiar nos municípios menores e geograficamente menos localizados, isto é, desprovidos de escolas de boa qualidade e até mesmo de escolas do ensino médio, bem como de estradas que facilitassem o acesso a outros locais, não oferecendo condições para os estudantes do ensino fundamental concluir o ensino médio. Frequentar uma universidade ou faculdade e realizar o sonho de fazer um curso superior era uma possibilidade quase remota, quiçá uma utopia. No entanto, veio tornar-se real quando o governo do Estado do Tocantins através da Fundação Universidade do Tocantins/Unitins fez parceria com a EDUCON, atualmente EADCON, para oferecer, em fase experimental, o curso Normal Superior.

Essa iniciativa ofereceu oportunidades para que alunos recém-saídos do ensino médio e outros que já haviam terminado esse nível de ensino há mais tempo, retornassem à sala de aula, agora em um nível superior e em uma nova modalidade de ensino: a distância, denominada na época de curso 'telepresencial'. A pesquisa mostrou de forma clara essa situação por meio da forma que os egressos expressaram suas opiniões, elogios e sugestões ao CNST.

Com essa pesquisa, também foi possível perceber por meio das evidências que o acesso às informações e à ampliação dos conhecimentos proporcionaram uma grande transformação na vida não só dos ex-alunos, mas também da sua comunidade local.

Com o título a eles conferido e a consequente ascensão profissional, o aumento salarial proporcionou-lhes um status social diferenciado, valorização pessoal e profissional, e, 
evidentemente, uma visão mais consciente da função da escola, da sociedade e do papel do professor. Da mesma forma, o curso foi fundamental para a elevação da autoestima, melhoria nos relacionamentos interpessoais com familiares e amigos, bem como no ambiente de trabalho.

Paralelamente, foi possível também, de forma gradativa, a aquisição de bens materiais como a melhoria nas condições de moradia, a compra de eletrodomésticos, o auxílio aos familiares menos favorecidos, além da oportunidade de dar continuidade aos estudos na realização de cursos de especialização e aprovação em concursos públicos.

O CNST representou um marco na história educacional, social e cultural do estado do Tocantins, sendo um “divisor de águas” na vida dos egressos e, consequentemente, na vida das pessoas de cada município tocantinense, onde o curso foi implantado, possibilitando um novo olhar, um horizonte mais amplo atrelado a novas oportunidades na vida pessoal e profissional desses egressos, bem como a chance de exercer a cidadania de forma consciente, com vistas a uma sociedade mais justa, mais humana e igualitária.

É da Universidade que esperamos a produção do conhecimento científico, tecnológico e humanístico para superar os obstáculos e desajustes que ainda afligem esta sociedade já globalizada. $\mathrm{O}$ momento em que se vive faz com que busquemos um sentido para a própria existência, produzindo nas pessoas, em particular nos profissionais da educação, objeto deste estudo, a necessidade de acreditar em algo tão forte e especial que sua capacidade de agir transcenda ao do ser humano comum.

Pode-se afirmar que o profissional com formação superior, principalmente na área da Educação, produz frutos benéficos para si e para os demais com quem convive, pois, quando desenvolve suas competências, através de projetos socioeducativos, está contribuindo significativamente para que haja mudança social e educativa que se quer.

Pela relevância dos resultados oriundos dessa pesquisa, surgiram possibilidades e sugestões de projetos na modalidade a distância para novos cursos de graduação e pós-graduação em outras áreas, bem como novas pesquisas e produções acadêmicas.

\section{REFERÊNCIAS}

BIRGIN, Alejandra. La docencia como trabajo: la construcción de nuevas pautas de inclusión y exclusión. In: GENTILI, Pablo; FRIGOTTO, Gaudêncio (Compiladores). La ciudadanía negada: políticas de exclusión en la educación y el trabajo. Buenos Aires: CLACSO: ASDI, 2002.

BRITO, Gláucia da Silva; PURIFICAÇÃO, Ivonélia da. Educação e novas tecnologias: um repensar. Curitiba: IBPEX, 2009.

CASTELLS, Manuel. A sociedade em rede. São Paulo: Paz e Terra, 1999.

CHIZZOTTI, Antonio. Pesquisa qualitativa em ciências humanas e sociais. Petrópolis: Vozes, 2006.

DENZIN, Norman K.; LINCOLN, Yvonna S. O planejamento da pesquisa qualitativa. Teorias e abordagens. 2 ed. Porto Alegre: Artmed, 2006. 
FREIRE, Paulo. Pedagogia do oprimido. Porto Alegre: Artes médicas, 1970.

FRIGOTTO, Gaudêncio; GENTILI, Pablo. A Cidadania Negada - Políticas de Exclusão na Educação e no Trabalho. São Paulo: Cortez, 2002.

GADOTTI, M. A. Histórias das ideias pedagógicas. São Paulo: Ática, 1995.

GARCÍA CANCLINI, N. Cultura y organización popular. Cuadernos Políticos, número 38, Ediciones Era, México, D. F., enero-marzo 1984. p. 75-82.

KENSKI, Vani M. Tecnologias e Ensino Presencial e a Distância. Campinas/SP: Papirus, 2003.

KENSKI, Vani M. Educação e tecnologias. São Paulo: Ed. Inesp, 2005.

LANDIM, Cláudia M. Educação a distância: algumas considerações. Rio de Janeiro: RJ, 1997.

LAVILLE, Christian; DIONNE, Jean. Tradução de Heloísa Monteiro e Francisco Settineri. A construção do saber - Manual de metodologia da pesquisa em ciências humanas. Porto Alegre: Artes Médicas; Belo Horizonte: UFMG, 1999.

LIBÂNEO, José Carlos. Pedagogia e pedagogos, para quê? 10. ed. São Paulo: Cortez, 2008.

LITWIN, Edith (Org.). Educação a distância: temas para o debate de uma nova agenda educativa. Porto Alegre: Artmed, 2001.

PIMENTA, Selma Garrido (Org). Pedagogia e pedagogos: caminhos e perspectivas. São Paulo: Cortez, 2002.

SAVIANI, Dermeval. Escola e democracia. 24 ed. São Paulo: Cortez: Autores Associados, 1991, SAVIANI, Dermeval (Org.) et al. Capitalismo, Trabalho e Educação. Campinas, SP: Autores Associados 2002. 
i O Poder Público incentivará o desenvolvimento e a veiculação de programas de ensino a distância, em todos os níveis e modalidades de ensino, e de educação continuada (art 80 LDB).

ii A formação em Normal superior insere-se no contexto das Diretrizes Curriculares Nacionais - DCN, para o Ensino Fundamental (Parecer CEB/CNE n. 04/98) e também os pareceres 15/98 e 22/98 tratam das diretrizes norteadoras da educação infantil e do ensino fundamental e médio, além da LDB, hoje superado pelas mudanças do Curso de Pedagogia.

iii “En esa estructuración se arraiga La hegemonía: en la interiorización muda de la desigualdad social bajo la forma de disposiciones inconscientes en el propio cuerpo, en la conciencia de qué es lo posible y qué lo inalcanzable”. 